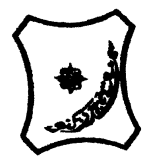

Bayero Journal of Pure and Applied Sciences, 10(1): 243 - 246

ISSN 2006 - 6996 \title{
ARBUSCULAR MYCORRHIZAL FUNGAL INOCULANTS ON YIELD COMPONENTS OF CASSAVA IN NORTHERN GUINEA SAVANNA ALFISOLS OF NIGERIA
}

INTERACTION BETWEEN PHOSPHORUS FERTILIZER AND

\author{
Aliyu*, I. A. and Yusuf, A.A. \\ Department of Soil Science, Institute for Agricultural Research, Ahmadu Bello University P.M.B. 1044, \\ Zaria, Nigeria \\ *Corresponding Author: ibrabuba@gmail.com; iaaliyu@abu.edu.ng. Tel: 08057784973
}

\begin{abstract}
Field experiment was carried out in the Northern Guinea Savanna agro-ecology of Nigeria to examine the interaction between Phosphorus (P) fertilizer and Arbuscular Mycorrhizal Fungal (AMF) inoculants on cassava yield components. The experiment was laid in a split plot design with $P$ fertilizers as main plot and AMF inoculants as subplots. There were three rates of $P(0$, 17.5, and $35 \mathrm{~kg} \mathrm{P}_{2} \mathrm{O}_{5} \mathrm{ha}^{-1}$ ) and three levels of $\mathrm{AMF}$ inoculants (Control, Glomygel and Mycodrip). The result showed a significant interaction between $P$ and AMF in root/shoot ratio and mycorrhizal response ratio. Highest root/shoot was recorded with combination of 17.5 $\mathrm{P}_{2} \mathrm{O}_{5} \mathrm{ha}^{-1}+$ control which depict increased sink strength. However, at $\mathrm{O} \mathrm{kg}_{2} \mathrm{O}_{5} \mathrm{ha}^{-1}$, Glomygel and Mycodrip were $65.5 \%$ and $21.5 \%$ respectively greater than control. Mycorrhizal response was also shown to be highest with application of $\mathrm{O} \mathrm{kg} \mathrm{P}_{2} \mathrm{O}_{5} \mathrm{ha}^{-1}+\mathrm{Glomygel}$ showing much influence of the inoculants where no $P$ was applied. Single effects of $P$ and AMF showed that dry yield components were significantly $(p<0.01)$ increased. The root dry weight was increased by 3.21 and $5.16 \mathrm{tha}^{-1}$ as a result of application of $17.5 \mathrm{~kg} \mathrm{P}_{2} \mathrm{O}_{5} \mathrm{ha}^{-1}$ and $35 \mathrm{~kg} \mathrm{P}_{2} \mathrm{O}_{5}$ $\mathrm{ha}^{-1}$ respectively over application of $0 \mathrm{~kg} \mathrm{P}_{2} \mathrm{O}_{5} \mathrm{ha}^{-1}$. Glomygel and Mycodrip inoculants recorded $28 \%$ and $4 \%$ total plant dry yield increment respectively over control. This study shows that both $P$ and AMF increased dry yield of cassava in Northern Guinea Savanna of Nigeria. The reproducibility at scale and in time is required for proper recommendation.

Keywords: AMF inoculants, Cassava, Alfisol, Mycorrhizal response, $P$ fertilizers.
\end{abstract}

INTRODUCTION

Phosphorus $(\mathrm{P})$ is one of the most important determinants for plant growth and its low availability in soil decreases shoot growth. Unfortunately, widespread occurrence of $P$ deficiency is reported in most arable lands in Nigeria. For example Kamara et al. (2008) reported that $P$ levels were lower than critical values in $92 \%$ of the fields surveyed in the Northern Guinea Savanna of Nigeria. Overcoming this problem is one of the major challenges the smallholder farmers face in increasing crop production. Therefore, $\mathrm{P}$ fertilizers are necessary inputs in order to obtain optimal crop yields. However, inorganic $P$ fertilizers are not readily available and/or the resource-poor farmers cannot afford them. Hence there is need to provide alternative in order to increase productivity in a low-input manner.

Soil microbes, specifically arbuscular mycorrhizal fungi (AMF), serve as good alternatives as they offer potential to increase yields and productivity in a low-input systems. Cassava in particular, is tolerant to soils with low levels of $P$ because it forms a beneficial association with AMF, which allows the crop to absorb sufficient $P$ for healthy growth.
Manipulation through inoculation with AMF has led to growth increases in cassava root by approximately 20\%(Rodriguez and Sanders, 2015).

Although high soil $P$ level is reported to decrease formation and growth of AMF, It only happens when $P$ is applied homogenously to the soil in pot experiments under controlled conditions. Under field conditions the influence of fertilizer $P$ on AMF community structure and abundance is variable. Recent study by Gosling et al. (2013) indicated that high soil P supply would not always have a negative impact on AMF community. In addition, Howeler et al. (1987) reported that AMF species vary in their relative effectiveness at different $P$ concentrations in the soil solution. In their experiment, they found that when isolates of 5 AMF inoculants were evaluated with application of 5 levels of $P$, none of the isolates was very effective without $P$ application. This stands for a reason that inoculation of cassava with AMF will give a significant yield when combined with $P$ fertilizer. The aim of this study therefore is to examine the combined effect of $P$ fertilizer and AMF inoculants on the dry yield components of cassava in Northern guinea savanna Alfisols of Nigeria. 


\section{MATERIALS AND METHODS}

The experiment was conducted on the research farm of the Institute for Agricultural Research (IAR) Samaru Nigeria (N11010'31.3”, E007 36 '38.9" and $704 \mathrm{~m}$ ). The field was cleared, ploughed, harrowed and ridged at 75 $\mathrm{cm}$ apart using tractor. The field was then divided according to experimental treatments using pegs. There were total number of 36 plots and each plot size was $72 \mathrm{~m}^{2}$. The cassava variety planted was TME 419 when rain was fully established. The experiment was laid down in split plot design and treatments included three (3) phosphorus levels as main plots $\left(0,17.5\right.$, and $\left.35 \mathrm{~kg} \mathrm{P}_{2} \mathrm{O}_{5} \mathrm{ha}^{-1}\right)$ and three (3) AMF inoculants levels as subplots (Control, Glomygel, Mycodrip). The total treatments therefore, were 9 and replicated 4 times giving total number of 36 plots. The application of fertilizer was done based on the recommendation made by National Root Crop Research Institute (NCRI) of Nigeria at $90 \mathrm{~kg} \mathrm{~N}$ $\mathrm{ha}^{-1}, 35 \mathrm{~kg} \mathrm{P}_{2} \mathrm{O}_{5} \mathrm{ha}^{-1}$, and $75 \mathrm{~kg} \mathrm{~K}_{2} \mathrm{O} \mathrm{ha}^{-1}$. While $\mathrm{N}$ and $\mathrm{K}$ were applied uniformly as recommended, $\mathrm{P}$ was applied according to the treatments.

Two inoculants (Glomygel and Mycodrip) were obtained in concentrated form and diluted before application (Glomygel was diluted in the ratio 1:3 inoculant: water, application per stake was $2 \mathrm{ml}$; and Mycodripdiluted in the ratio 1:9 inoculant: sand, application per stake was $2 \mathrm{~g}$ )as recommended by the Producers. Inoculation was done at 20 days after planting by carefully lifting the cassava stem cuttings and applying the inoculants beneath the stem cuttings.

Harvesting was done at 12 months after planting. A net plot of $12 \mathrm{~m}^{2}$ consisting of 12 plants was marked in each plot and the plant samples were taken therein. Root samples were taken and oven dried at $70^{\circ} \mathrm{C}$ until constant weight.

All data collected were subjected to analysis of variance using SAS software 9.4. Where significant $F$ values were observed, Tukey's studentized test of significant (HSD) was used to separate the means. The mycorrhizal response (MR) ratio of root dry weight was determined to evaluate the effects of AMF inoculation on harvestable root yield. This is given by:

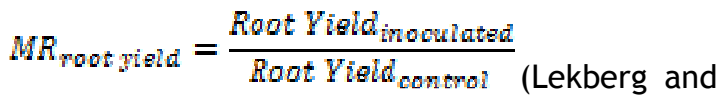
Koide, 2005)

\section{RESULTS}

Analysis of root dry weight showed that application of $\mathrm{P}$ fertilizer significantly $(p<0.001)$ increased the root dry yield (Table 1). Application of $17.5 \mathrm{~kg} \mathrm{P}_{2} \mathrm{O}_{5} \mathrm{ha}^{-1}$ and $35 \mathrm{~kg} \mathrm{P}_{2} \mathrm{O}_{5}$ $\mathrm{ha}^{-1}$ increased dry root yield by 3.21 and $5.16 \mathrm{t}$ $\mathrm{ha}^{-1}$ respectively. This trend was also observed in the shoot dry weights and ultimately the total plant dry yield. Highly significant $(p<0.001)$ root: shoot ratio was also recorded due to application of $P$ implying more assimilate was translocated to the root (Table 2).Analysis of the effect of $P$ on MR showed that MR decreased with application of P. Application of AMF inoculants also recorded a highly significant $(p<0.01)$ difference among the measured parameters. Significantly higher root dry weight $(20 \%)$, shoot dry weight $(42 \%)$ and total plant dry biomass (28\%) was observed over control as a result of inoculation with Glomygel.

Table 1: Effect of $\mathrm{P}$ and AMF on the dry yield components of cassava ( $\left.\mathrm{t} \mathrm{ha}^{-1}\right)$

\begin{tabular}{|c|c|c|c|c|c|}
\hline Treatment & Root & Shoot & Root/ Shoot & Total Plant & MR ratio \\
\hline \multicolumn{6}{|l|}{ P Level (P) } \\
\hline 0 & $3.49 c$ & $3.02 \mathrm{~b}$ & $1.16 \mathrm{~b}$ & $6.51 \mathrm{c}$ & $1.57 a$ \\
\hline 17.5 & $6.70 \mathrm{~b}$ & $3.55 b$ & $1.93 a$ & $10.25 b$ & $1.08 \mathrm{~b}$ \\
\hline 35 & $8.65 a$ & $5.39 a$ & $1.73 a$ & $14.04 a$ & $0.93 b$ \\
\hline SED & 0.54 & 0.33 & 0.20 & 0.63 & 0.13 \\
\hline \multicolumn{6}{|l|}{ Inoculant (I) } \\
\hline Glomygel & $7.21 a$ & $4.68 \mathrm{a}$ & 1.64 & $11.89 a$ & $1.48 \mathrm{a}$ \\
\hline Mycodrip & $5.64 b$ & $3.99 \mathrm{~b}$ & 1.40 & $9.63 b$ & $1.10 \mathrm{~b}$ \\
\hline Control & $5.99 \mathrm{~b}$ & $3.29 c$ & 1.78 & $9.28 \mathrm{~b}$ & $1.00 \mathrm{~b}$ \\
\hline SED & 0.54 & 0.33 & 0.20 & 0.63 & 0.13 \\
\hline \multicolumn{6}{|l|}{ Interaction P x I } \\
\hline Significance & NS & NS & * & NS & $* *$ \\
\hline
\end{tabular}


Significant $(p<0.05)$ interaction was recorded in the root/shoot ratio. Figure 1 showed a significantly higher root/shoot ratios trend from Glomygel to Control at $0 \mathrm{~kg} \mathrm{P}_{2} \mathrm{O}_{5} \mathrm{ha}^{-1}$. However, with application of $17.5 \mathrm{~kg} \mathrm{P}_{2} \mathrm{O}_{5} \mathrm{ha}^{-1}$, control gave highest root/shoot ratio.

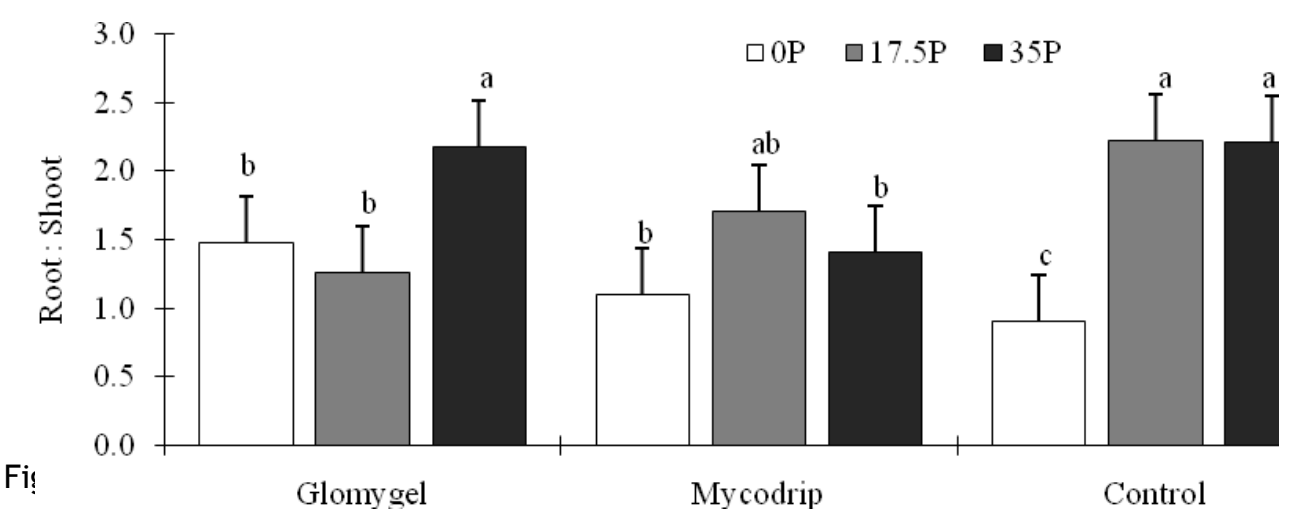

A highly significant $(p<0.01)$ interaction between $\mathrm{P}$ and I was observed in the MR. This is presented in fig 2 . Here, control was taken as reference point, which is 1 . Any treatment above control shows MR. Generally, application

of $0 \mathrm{P}_{2} \mathrm{O}_{5} \mathrm{ha}^{-1}+$ Glomygel showed highest $\mathrm{MR}$ followed by $0 \quad \mathrm{P}_{2} \mathrm{O}_{5} \mathrm{ha}^{-1}+$ Mycodrip. Also, application of $17.5 \mathrm{P}_{2} \mathrm{O}_{5} \mathrm{ha}^{-1}+$ Glomygel showed a high MR (Fig 2).

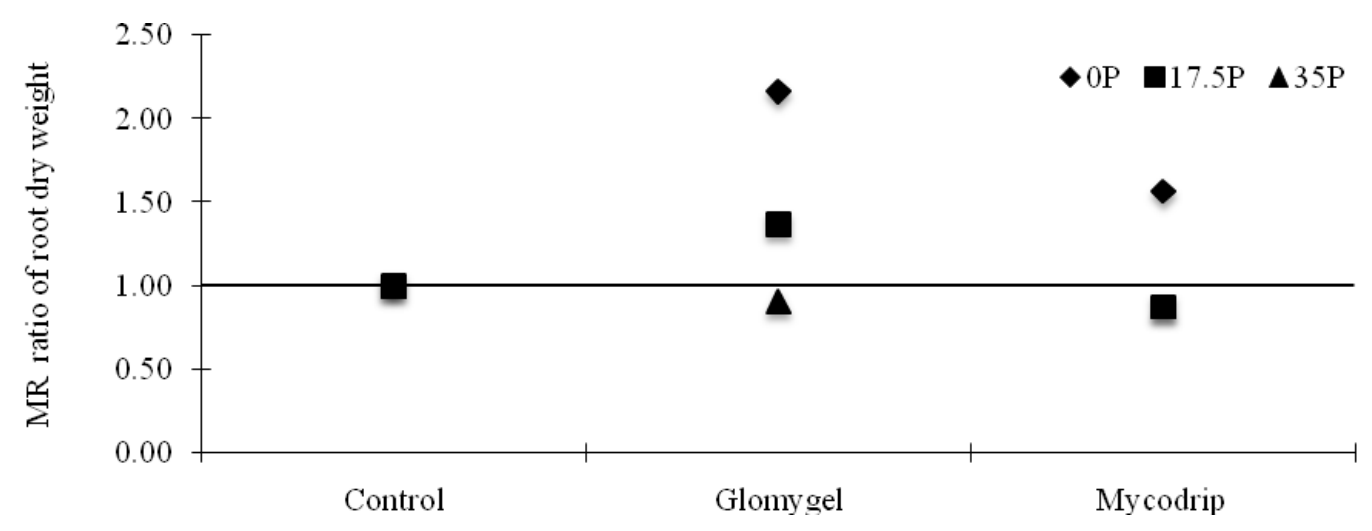

Fig 2: Effects of different $P$ rates and $A M F$ inoculants on $M R$ ratio.

\section{DISCUSSION}

The current study shows that dry yield components of cassava were increased as a result of application of $P$ fertilizers. This is because $P$ is central to yield of cassava as the rate of growth, development and tuber yield is controlled by soil nutrients such as P. Sanginga and Woomer (2009) reported that P is indispensible for cassava tuber. Higher root: shoot ratios were observed as a result of $P$ application, which depicts more partitioning of assimilates to roots than shoots. This indicated a remarkable positive effect of $P$ fertilization on the sink strength. Fermont et al.(2010) reported that yield increases due to fertilizer application were as the result of an increased sink capacity i.e. increased number of storage roots per plant. Inoculation with AMF also significantly increased the dry yield components of cassava. The AMF inoculants are known to increase the growth and yield of cassava (Rodriguez and Sanders, 2015) through increased net photosynthesis, enhanced water and nutrient uptake.

The significant interactions between $P$ fertilizers and AMF inoculants especially on the harvestable root dry yield (MR) showed that the AMF inoculants increased in their effectiveness with some application of $\mathrm{P}$. It has been reported that AMF species vary in their relative effectiveness at different $P$ concentrations in the soil solution (Howeler et al., 1987).

Conclusion

Our study on dry yield component of cassava shows that yield was greatly enhanced by applying both $\mathrm{P}$ fertilizers and AMF inoculants. Different combinations of $P$ and AMF inoculation increased the harvestable root dry 
yield of cassava, which showed higher yield of cassava as a result of $\mathrm{P}$ application and AMF inoculation. It would be important to assess the

\section{Acknowledgement}

The authors would like to express their sincere gratitude to the International Institute of

\section{REFERENCES}

Fermont A.M., Tittonell, P.A., Baguma, Y., Ntawuruhunga, P. and Giller, K.E. (2010). Towards understanding factors that govern fertilizer response in cassava: lesson from east Africa. Nutrient Cycle in Agroecosystem, 86:133-155.

Gosling, P., Andrew, M., Maude, P., Hammond, J.P. and Bending, G.D. (2013). Contrasting arbuscular mycorrhizal communities colonizing different host plants show a similar response to a soil phosphorus concentration gradient. New Phytologist,198:546-556.

Howeler, R.H., Sieverding, E. and Saif S. (1987). Practical aspect of mycorrhiza technology in some tropical crop and pasture. Plant and Soil,100: 249-283.

Kamara, A.Y., Kwari, J., Ekeleme, F., Omoigui L. and Abaidoo, R.C. (2008). Effect of phosphorus application and soybean cultivar on grain and dry matter yield of subsequent maize in the tropical savannas of northeastern Nigeria. African Journal of Biotechnology, 7(15): 25932599. reproducibility of the findings at scale and in time for better recommendations.

Tropical Agriculture (IITA) for sponsoring this work under the auspices of COMPRO II project funded by Bill and Melinda Gates Foundation.

Lekberg, Y. and Koide, R.T. (2005). Is plant performance limited by abundance of arbuscular mycorrhizal fungi? A meta-analysis of studies published between 1988 and 2003. New Phytologist, 168: 189-204.

Rodriguez, A. and Sanders, I.R. (2015). The role of community and population ecology in applying mycorrhizal fungi for improved food security. International Society of Microbial Ecology, 9:1053- 1061.

Sanginga, N. and Woomer, P.L. (2009). Cassava and its current management. In: Integrated Soil Fertility Management in Africa--Principles, Practices and Developmental Process. pp. 100-102. 